\title{
BN, Rat Strain
}

National Cancer Institute

\section{Source}

National Cancer Institute. BN, Rat Strain. NCI Thesaurus. Code C14395.

An inbred strain of Rattus norvegicus derived from Silvers and Billingham stock (1958),

characterized by a non-agouti brown coat color and RT 1n MHC haplotype. 